\title{
On the Variation of Fatigue-crack-opening Load with Measurement Location
}

\author{
Experimental results indicate that the point of linearity \\ on the displacement-load relation is a variable, dependent on \\ measurement location relative to the crack tip, and not a true \\ measure of the unique crack-tip-opening load
}

by D.E. Macha, D.M. Corbly and J.W. Jones

ABSTRACT - The work presented here evaluates the validity of using the load at the point of linearity on the displacementload curve, as suggested by Elber, as an experimental measure of the crack-tip-opening load. Displacement-load behavior was investigated for a fatigue-cracked modified compact specimen of a nickel-base superalloy. Displacements were determined at the notch mouth using a standard clip-on gage, along the crack sufrace using a laser-interferometric displacement gage and, in the plastic zone ahead of the crack, using an opticalinterferometry technique. Acoustic-emission monitoring was employed as a means to detect potential crack extension during measurement-load cycles and to detect physicalcrack closure.

The magnitude of the crack-tip-opening load, as determined from these measurements, is dependent on the distance from the crack tip at which the measurement is made. As an additional means of evaluating the crack-tip-opening load, crack-surface profiles are constructed from the displacementload measurements made behind the crack tip. A discussion is given concerning the significance of these results in evaluating the validity of using the load at the point of linearity as a parameter to quantify crack closure.

\section{Introduction}

The use of linear-elastic-fracture-mechanics (LEFM) methods for the design of advanced aerospace structures has rapidly expanded since 1970 . In general, the use of LEFM has resulted in more-durable structures because of its ability to incorporate the influence of preexisting defects on the life of the structure. For many applications, this has changed the basic design philosophy from crack initiation to crack propagation. Experience has shown that

D.E. Macha is Materials Engineer, Air Force Materials Laboratory, Wright-Patterson Air Force Base, OH 45433. D.M. Corbly is Research Engineer, Aircraft Engine Group, General Electric Company, Evendale, $\mathrm{OH}$ 45215. J.W. Jones is associated with Materials and Metallurgical Engineering Department, University of Michigan, Ann Arbor, MI 48104.

Paper was presented at 1979 SESA Spring Meeting held in San Francisco, CA on May 20-25.

Original manuscript submitted: April 5, 1978. Final version received: January 19, 1979. one must be cautious when applying LEFM to predict either crack-growth behavior or the residual life of an engineering structure. It is recognized that few engineering materials exhibit linear-elastic behavior at the crack tip, but rather the material adjacent the tip of a propagating crack undergoes plastic deformation prior to fracture.

A common approach to account for the effect of the crack-tip plastic deformation on fatigue-crack-growth behavior is to derive an empirically based crack-growth model that alters the conventional linear-elastic stressintensity parameter, $K$, to create an effective stress intensity experienced locally at the crack tip. One such approach that has received considerable attention is the crack-closure theory developed by Elber. ${ }^{1.2}$

In his early work,' Elber conducted an analysis of the stress distribution acting on the fracture surfaces of a fatigue crack at zero load after the crack had been propagating under zero-tension loading. The results of his study indicated that crack surfaces may be partially or completely closed at zero load. In addition, he found the resulting local compressive-stress maxima may exceed the yield stress of the material. From his analysis, Elber concluded in part that, when the load applied to a fatigue crack grown under cyclic tension is reduced to zero, compressive residual stresses are present along the cracked section and part of the plastic zone ahead of the crack tip.

Elber attributed the noted residual compressive stresses behind the crack tip to the crack-closure phenomenon. He postulated that crack closure was a direct result of the permanent plastic deformations left in the wake of a propagating fatigue crack. Due to crack closure, a crack in a fatigue specimen is fully open for only a part of the load cycle, as the initial portion of the loading cycle serves only to overcome the compressive residual stresses along the crack line.

An appreciation for the importance of crack closure is realized when one considers that the stress distribution at the tip of a propagating fatigue crack first experiences the singularity of the theoretically sharp crack only after the crack is completely open to the crack tip. Therefore, under constant amplitude loading, the loading conditions experienced locally at the crack tip cannot be solely 
characterized by the stress-intensity range $(\Delta K)$ calculated using the remotely applied stress range $(\Delta \sigma)$. It is more appropriate to characterize the loading conditions experienced at the crack tip by using an effective stressintensity range $\left(\Delta K_{e f f}\right)$ calculated using only that portion of the remotely applied stress range actually experienced at the crack tip. This effective stress range $\left(\Delta \sigma_{e f f}\right)$ was defined by Elber as:

$$
\Delta \sigma_{e f f}=\sigma_{\max }-\sigma_{\text {open }}
$$

where $\sigma_{\max }$ is the maximum value of remotely applied stress and $\sigma_{\text {open }}$ is that value of remotely applied stress required to completely separate the crack surfaces.

Elber demonstrated the occurrence of crack-tip closure and the utility of the concept of an effective stress-intensity range in predicting the dependence of fatigue-crack-growth rate on the stress ratio, $R$. This apparent success of the crack-closure concept led to considerable effort to refine the experimental techniques for measuring the magnitude of crack-tip closure. These techniques are generally divided into two categories; techniques which measure bulkspecimen response, and those which measure displacements on the specimen surface. Bulk measurements have been made using electrical-potential methods, ${ }^{3}$ ultrasonics, ${ }^{4}$ acoustic emission ${ }^{5}$ and, for transparent materials, optical interferometry. ${ }^{\circ}$ Specimen-surface-displacement measurements have been made with strain gages bonded across the crack line, ${ }^{7}$ displacement transducers attached across the crack line or ahead of the crack tip,,$^{2,8}$ optical-interferometry techniques, ${ }^{9-11}$ and clip-on displacement gages at the notch mouth. ${ }^{12}$

To quantify crack closure, most researchers have attempted to determine the applied load at which the crack is fully open, i.e., no physical contact occurs between the crack surfaces. The crack-opening load, $P_{o p}$, as defined by Elber ${ }^{2}$ and shown here in the idealized displacement-load curve in Fig. 1, is the load at the transition point from nonlinear to linear behavior. In his original analysis, Elber $^{2}$ assumed the crack-surface displacement was a function only of load and crack length. For a partially closed crack, the elastic displacement-load behavior is not linear but is a function of the effective crack length. Based on these assumptions, the determination of the point of linearity as shown in Fig. 1 defines the load at which the crack is fully open.

The majority of opening-load determinations, regardless of the experimental techniques used, are based on the above assumptions concerning displacement-load behavior. However, despite the numerous sophisticated techniques utilized, a considerable amount of conflicting crackclosure data exists in the literature. Conflicting results on the dependence of $P_{\mathrm{o} p}$ on maximum stress intensity, $K_{\max }$, and $R^{2,3}$ question the validity of crack closure for incorporation into crack-propagation models. It has also been observed that bulk measurements often yield a higher $\boldsymbol{P}_{o p}$ than do measurements of displacements on the specimen surface. ${ }^{12,13}$ Some efforts have been made to match bulk results with surface results by various schemes of extrapolating the bulk-measurement data.4.14 Such techniques assume $a$ priori the uniqueness of $\boldsymbol{P}_{o p}$ as determined by specimen-surface-displacement measurements. Several investigations $s^{9,12,15}$ have indicated that the validity of this assumption is questionable.

In an effort to resolve this apparent conflict, a rigorous evaluation of the crack-opening behavior of a modified compact specimen was conducted. A fatigue crack was

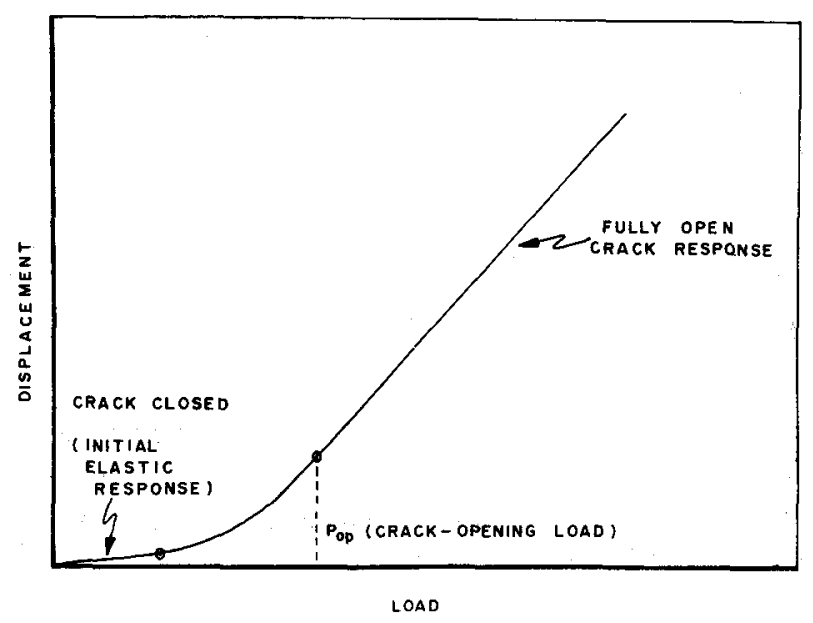

Fig. 1-Schematic displacement-load curve for crack experiencing crack closure

incrementally grown at a constant $K_{\max }$ and $R$. The crackopening behavior was evaluated at six different crack lengths. The displacement-load behavior was evaluated both in front of and behind the crack tip using two optical-interferometry techniques and the bulk behavior was evaluated using acoustic emission and clip-on displacement-gage techniques.

\section{Experimental Technique}

In the experimental work described here, displacement measurements were made at room temperature on a modified compact specimen $(H / W=.486)$ as shown in Fig. 2. The equation used to calculate the stress-intensity factor $(K)$ for this specimen geometry is taken from Ref. 16 as:

$$
K=\frac{P \sqrt{a} Y}{B W}
$$

where $P$ is the applied load, $a$ the crack length as measured on the specimen surface, $B$ and $W$ the specimen thickness and width, respectively, and $Y$ the calibration factor defined as:

$$
\begin{gathered}
Y=30.96-195.8(a / W)+730.6(a / W)^{2}-1186.3(a / W)^{3} \\
+754.6(a / W)^{4}
\end{gathered}
$$

The material evaluated was Gatorized ${ }^{\mathrm{TM}}$ IN-100, a nickel-base superalloy, with $\sigma_{y}=1.12 \times 10^{3} \mathrm{MN} / \mathrm{m}^{2}$ and $E=2.14 \times 10^{5} \mathrm{MN} / \mathrm{m}^{2}$. The room-temperature fracture toughness $\left(K_{I C}\right)$ of $\mathrm{IN}-100$ as determined by J-integral techniques is $157 \mathrm{MN} / \mathrm{m}^{3 / 2}$. $^{17}$ Fatigue-crack growth was conducted in a closed-loop servo-hydraulic testing machine operating at a cyclic frequency of $20 \mathrm{~Hz}$. The maximum stress intensity, $K_{\max }$, was held constant at $38.5 \mathrm{MN} / \mathrm{m}^{3 / 2}$ by periodically reducing the cyclic load as the crack extended. The crack length was measured on both specimen surfaces using Gaertner traveling microscopes. The average of the crack lengths measured on the two specimen surfaces was used to calculate the desired test load. This average surface-crack length is reported here. $R$ was maintained at 0.1 . At six selected crack lengths (Table 1), crack growth was interrupted and the specimen 


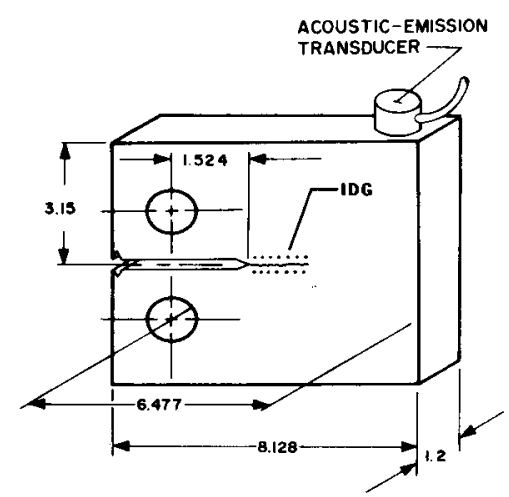

IDG SIDE

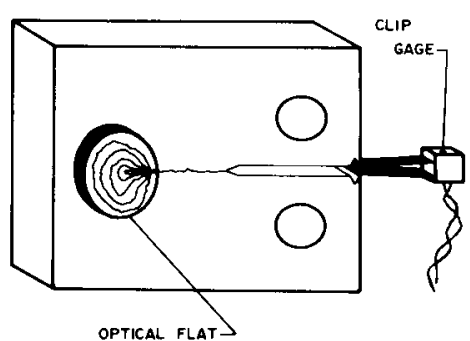

OPTICAL - INTERFEROME TRY SIDE
Fig. 2-Schematic of modified compact specimen $(H / W=.486)$ showing locations of various measurement techniques (all dimensions in centimeters) was removed to a screw-driven testing machine to make the displacement measurements. While making displacement measurements, care was taken to ensure that the specimen was not loaded to greater than 91 percent of the maximum load $\left(P_{\max }\right)$ used to extend the crack under cyclic loading. Displacement-load profiles were simultaneously obtained in three distinct regions (Fig. 2) of the

TABLE 1-CRACK LENGTH AND MEASUREMENT-LOCATION DATA FOR ALL IDG AND CLIP-ON DISPLACEMENT-GAGE MEASUREMENTS

\begin{tabular}{|c|c|c|}
\hline $\begin{array}{c}\text { Average Surface- } \\
\text { Crack Length } \\
(\mathrm{mm})\end{array}$ & $\begin{array}{l}\text { IDG } \\
\text { Locations } \\
(\mathrm{mm})\end{array}$ & $\begin{array}{l}\text { Clip-on-gage } \\
\text { Locations } \\
(\mathrm{mm})\end{array}$ \\
\hline 22.81 & $\begin{array}{l}.05,0.5,1.25 \\
2.5,3.75\end{array}$ & 39.32 \\
\hline 27.92 & $\begin{array}{l}0.5,1.25,2.5 \\
3.75,5.16,5.61 \\
6.36,7.61,8.86\end{array}$ & 44.43 \\
\hline 32.94 & $\begin{array}{l}0.5,1.25,2.5 \\
3.75,5.52,6.27 \\
7.52,8.77,10.18 \\
10.63,11.38,12.63 \\
13.88\end{array}$ & 49.45 \\
\hline 38.08 & $\begin{array}{l}0.1,0.5,2.5,3.73 \\
5.64,6.39,7.64 \\
8.89,10.66,11.41 \\
12.66,13.91,15.32 \\
15.77,16.52,17.77 \\
19.02\end{array}$ & 54.59 \\
\hline 43.28 & $\begin{array}{l}0.5,1.25,2.5,3.73 \\
5.3,5.7,7.7,8.93 \\
10.84,11.59,12.84 \\
14.09,15.86,16.61 \\
17.86,19.11,20.52 \\
20.97,21.72,22.97 \\
24.22\end{array}$ & 59.79 \\
\hline 48.36 & $\begin{array}{l}0.1,0.5,1.25,2.5 \\
3.73,5.58,6.33,7.58 \\
8.81,10.38,10.78 \\
12.78,14.01,15.92 \\
16.67,17.92,19.71 \\
20.94,21.69,22.94 \\
24.19,25.6,26.05 \\
26.8,28.05,29.3\end{array}$ & 64.87 \\
\hline
\end{tabular}

specimen: on one side of the specimen, along the crack line behind the crack tip using the interferometric displacement gage (IDG); ${ }^{18,19}$ on the other side of the specimen, in front of the crack tip using an optical-interferometry technique; ${ }^{20}$ and at the specimen-notch mouth using the clip-on displacement gage. In addition, acousticemission (AE) monitoring was performed during each loading cycle. The purpose of the AE measurements in this effort was to: (1) determine the magnitude of acoustic emission in IN-100 on a cycle-by-cycle basis, (2) monitor for crack extension, especially on the interior of the specimen during the test-loading cycles, and (3) evaluate the utility of acoustic emission as a method for detecting crack closure. A detailed description of the use of each measurement technique follows.

\section{Crack-opening-displacement (COD) Measurements}

The principles of the IDG are described in detail in Ref. 18 and 19. In this study, the IDG is used to measure the displacement that occurs between two indentations straddling the crack on the specimen surface. The indentations were applied $0.10 \mathrm{~mm}$ above and below the crack to give an operating gage length of $0.20 \mathrm{~mm}$. With the indentations placed close to the crack surfaces, it is assumed that the measured displacement occurring between the indentations is also that occurring between the crack surfaces at the specimen surface.

Upon extending the fatigue crack to the first test length, indentations were placed at distances of 0.050 , $0.50,1.25,2.5$ and $3.75 \mathrm{~mm}$ behind the crack tip. COD measurements were made, in turn, at each position during successive load cycles. This procedure was repeated at subsequent crack lengths using all available sets of indentations. Table 1 gives a listing of the IDG measurement positions behind the crack tip at each crack length evaluated.

During each load cycle at the respective crack lengths, displacements at the notch mouth were measured with a clip-on displacement gage of standard configuration (ASTM E 399-74). In contrast to the IDG measurements which were made at various locations relative to the crack tip during successive load cycles, the displacement gage at the notch mouth gave the displacement-load relationship at a fixed point relative to the crack tip (see Table 1).

The analog displacement-load data attained from both the IDG and clip-on displacement gage were reduced using a computer digitizing code that yielded digital displacement-load data suitable for analysis. A linear- 
regression analysis was used to determine the load at which the displacement-load curve became linear upon loading the specimen. Use of the regression analysis minimized the subjectivity in evaluating the data and ensured a consistent determination of the point of linearity.

A second analysis was conducted to determine the COD at all measurement locations for discrete load values. This program used a linear interpolation to determine the displacement associated with each load value. Cracksurface profiles were then constructed at 10,30, 50 and 90 percent of $P_{\max }$ for each crack length tested.

\section{Displacements in Front of Crack Tip}

In the region immediately ahead of the crack tip, an optical interferometry technique was used to measure the transverse displacements occurring during the fatigue cycle. This technique has been used to determine deformation zones $^{10,21-23}$ and average through-thickness strains ${ }^{22,23}$ in the crack-tip region. In the present experiment, a collimated beam of monochromatic light was directed through an optically flat quartz plate positioned directly on the polished specimen surface. During loading of the specimen, the separation between the specimen surface and the quartz flat, resulting from contraction at the crack tip, produces an optical-interference pattern. For normal incidence, the change in separation, $d$, is given for destructive interference as:

$$
d=\frac{n \lambda}{2}
$$

where $\lambda$ is the wavelength of the monochromatic light and $n$ is the order of the interference fringe. For the sodiumvapor light used, $\lambda=0.5893 \mu \mathrm{m}$ and the transverse displacement change between adjacent fringes is $0.2946 \mu \mathrm{m}$.

Video taping through a low-power microscope permitted recording of the optical-interference pattern during each test-load cycle. Small diamond-pyramid indentations placed along the projected crack plane allowed determination of real-time-displacement behavior at selected locations ahead of the crack tip. These data, when combined with the load-time trace, produced the desired

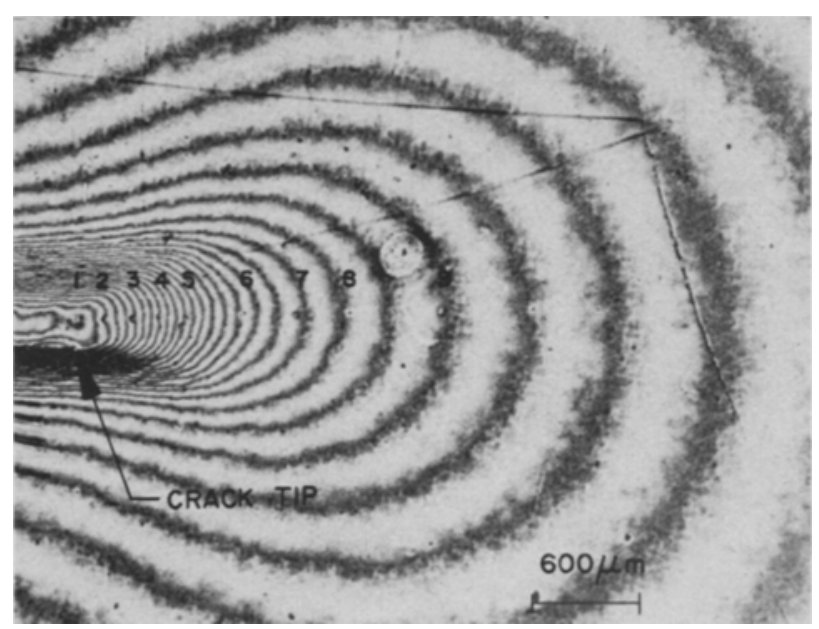

Fig. 3-Typical optical-interferometry fringe pattern around crack tip showing measurement locations. Crack length is $48.36 \mathrm{~mm}$

displacement-load record. Figure 3 shows a typical fringe pattern in the vicinity of the crack tip. Near the specimen surface, the shear lip causes the intersection of the crack plane with the surface to differ from the location of the interior crack plane. Note that the placement of the indentations is along the line of symmetry of the displacement field and not along the projected crack path on the surface. For consistency, all measurements were made along the line of symmetry.

\section{Acoustic-emission Measurements}

The AE technique has been used in recent years to study the fatigue-crack-growth process. ${ }^{5}$ Although there is not a complete understanding of the exact mechanisms which are uniquely related to various acoustic-emission sources, it is accepted that acoustic emissions occur upon crack extension. In some instances, it has been observed that acoustic emission occurs during the unloading portion
Fig. 4-Typical load-displacement data taken at a crack length of $38.08 \mathrm{~mm}$ using IDG and clip-on displacement gage. $\left(P_{o p}\right.$ on each curve denoted by dashed line)

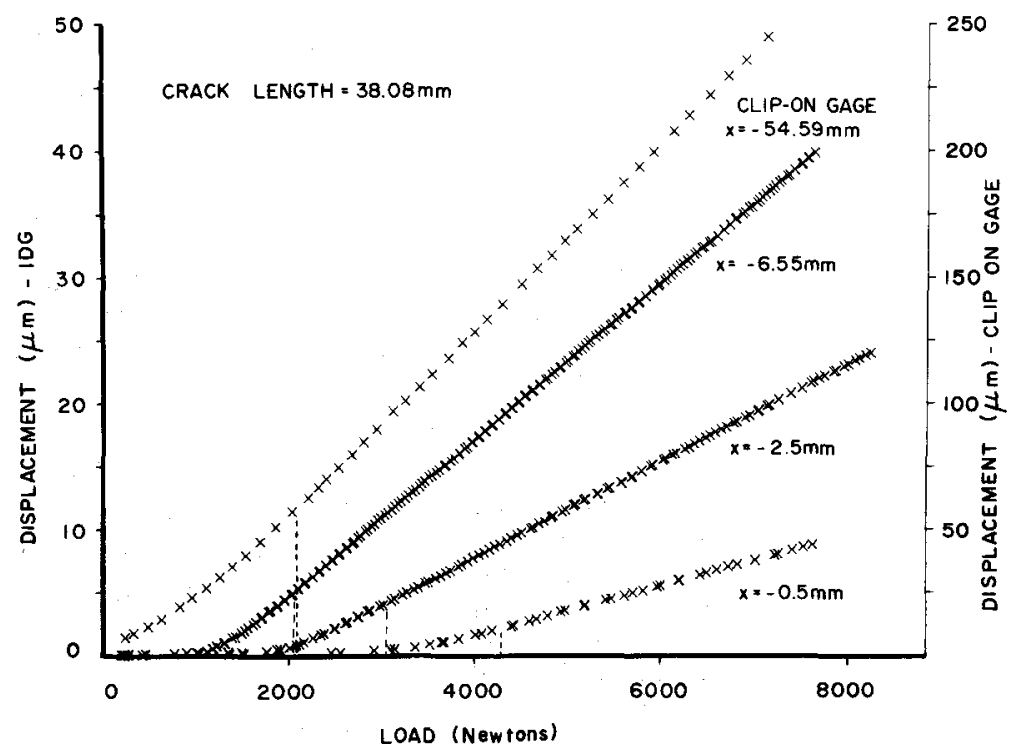




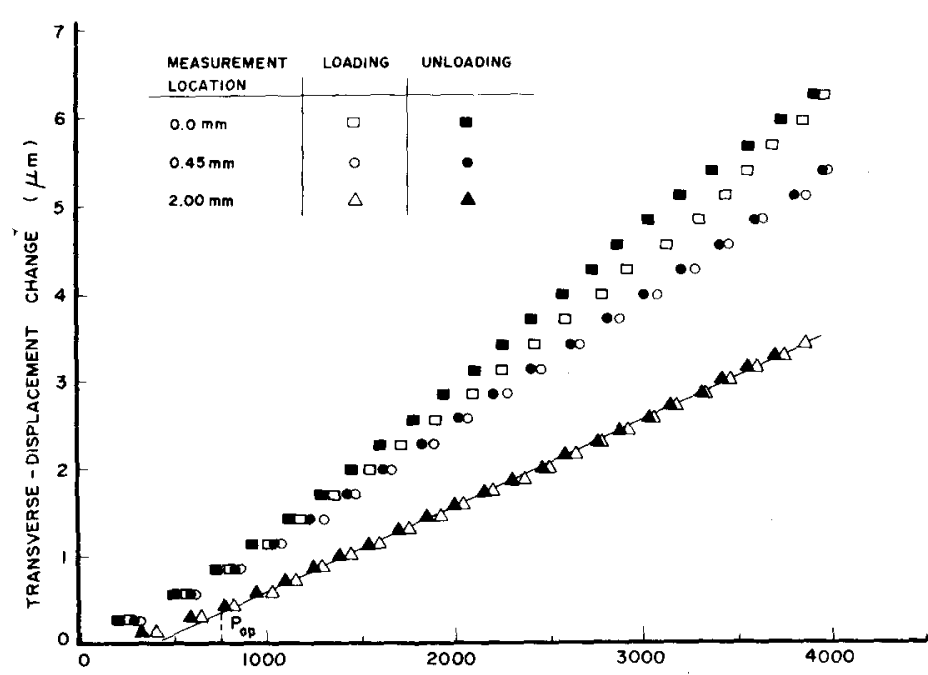

Fig. 5-Typical transverse displacement-load data at positions ahead of crack tip. Crack length is $48.36 \mathrm{~mm}$

of the fatigue-crack-propagation cycle. ${ }^{24}$

The acoustic-emission measurements reported herein were made with a Dunegan 3000 system including a Model 301 totalizer, Model 801 preamplifier, and a Model D9201 differential transducer. The transducer was coupled to the specimen with silicone vacuum grease in the position shown in Fig. 2. All measurements were made with a system gain of $89 \mathrm{~dB}$ and a $0.3-1.0 \mathrm{MHz}$ bandpass filter. These settings were chosen to maximize system sensitivity for emissions from the crack tip while minimizing extraneous noises from the test machine. Data were recorded on a dual-channel strip-chart recorder in the form of load vs. time and acoustic-emission counts vs. time.

\section{Results and Discussion}

The displacement-load behavior measured at $0.5,2.5$ and $6.55 \mathrm{~mm}$ behind the crack tip, using the IDG and at the notch mouth (54.59 mm behind crack tip) using the clip-on displacement gage, is shown in Fig. 4. From the data shown in Fig. 4, it is evident that as the measurement location approaches the crack tip the load at which the displacement-load relation becomes linear increases. As discussed earlier, when displacement measurements were being made, the specimen was loaded to 91 percent of $P_{\max }$ for cyclic growth. This precaution was taken to circumvent the introduction of new crack-tip plasticity as well as to minimize the chance for crack extension during the measurement cycles. As seen in Fig. 4, the displacement-load curves exhibit a significant linear range above the point of linearity.

The variation of the change in transverse displacement with load and distance in front of the crack tip as measured with the optical-interferometry method is shown in Fig. 5. Three features of these data merit consideration: (1) the displacement-load behavior measured near the crack tip exhibits hysteretic behavior; (2) the displacement is maximum at the crack tip and decreases as distance in front of the crack tip increases; (3) each displacementload record shows a transition from nonlinear to linear displacement-load behavior. The load at this transition point was interpreted as the opening load, $P_{o p}$, and was found to be sensitive to the distance from the crack tip at which the measurement was made.

The hysteresis in the displacement-load behavior occurred at each crack length investigated. The magnitude of this behavior was found to decrease with increasing distances from the crack tip. The quantitative nature of the extent of this hysteretic behavior and its use in determining the cyclic plastic-zone size is not currently understood.

In Fig. 6, the normalized $P_{o p}$ values $\left(P_{o p} / P_{\max }\right)$ for all measurements made in front of and behind the crack tip are plotted as a function of the measurement location relative to the crack tip. Near the crack tip, the value of $P_{o p}$ is strongly dependent upon measurement location. At a location $0.05 \mathrm{~mm}$ behind the crack tip, a normalized $P_{o p}$ value of 0.64 was measured. The values of $P_{o p}$ decrease continuously as the distance behind the crack tip increases. At distances greater than approximately 5.0$\mathrm{mm} P_{o p}$ becomes independent of measurement location stabilizing at an average value near 0.23 . From the results shown, the value of normalized $P_{o p}$ appears to be independent of crack length for this constant $K$ condition.

Although there is considerable test to test variation for measurements made ahead of the crack tip, those made within $1.0 \mathrm{~mm}$ of the crack tip also yield $P_{\text {op }}$ values that are highly sensitive to measurement location. At distances greater than $1.0-\mathrm{mm} P_{o p}$ values are approximately constant at 0.2 .

Based upon the behavior of $P_{o p}$ discussed above, one of

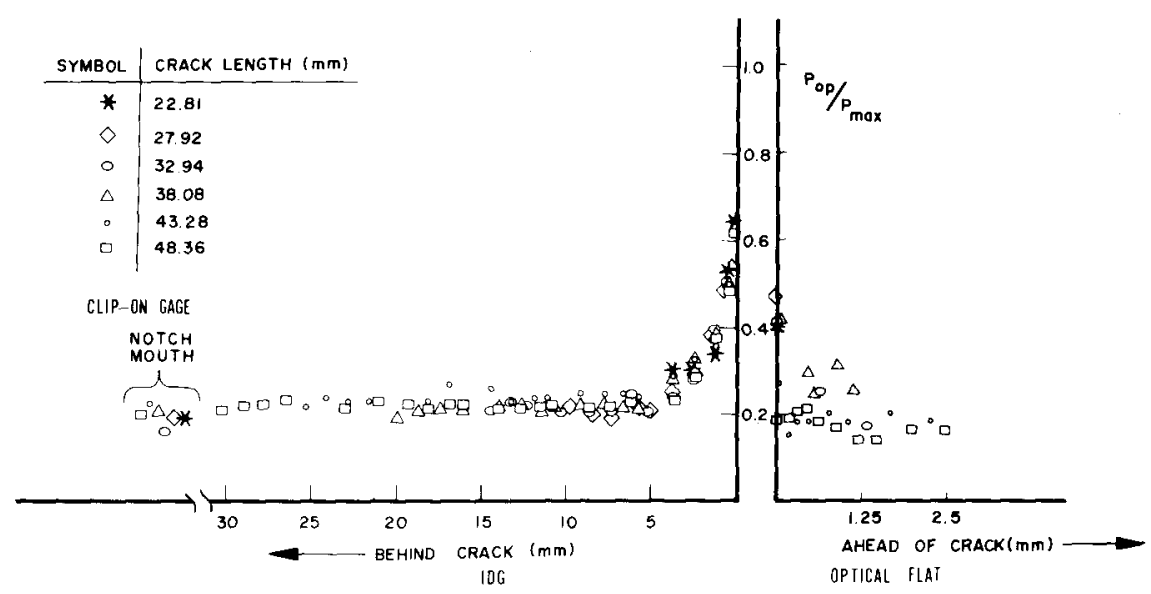

Fig. 6-Composite plot of normalized $P_{\text {op }}$ as a function of measurement location. All IDG, clip-on displacement gage and optical-interferometry data are shown 
Fig. 7-Crack-surface profiles in the nearcrack-tip region using IDG data

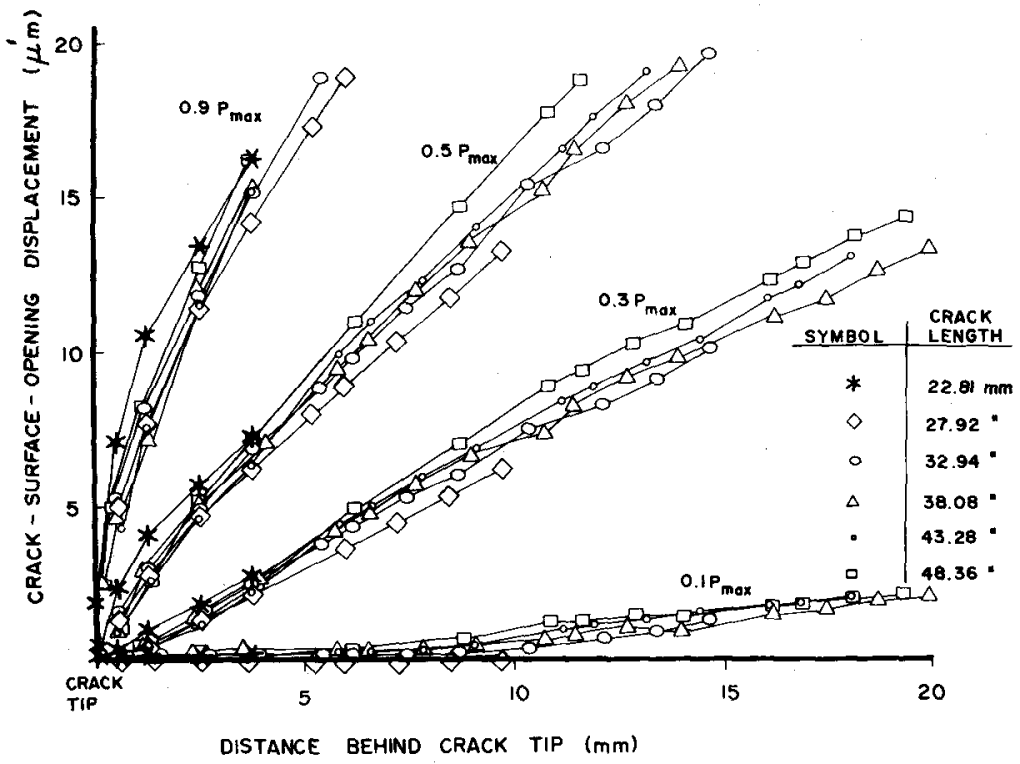

two positions may be accepted concerning the use of $\boldsymbol{P}_{\mathrm{op}}$ to quantify the crack-tip-opening load. First, since $P_{o p}$ as measured here is dependent on measurement location, it does not quantify the unique load at which total-cracksurface separation occurs. The second position assumes that $P_{o p}$ does quantify the unique opening load but the determination of $P_{o p}$ must be made at an appropriate location relative to the crack tip. The position of the appropriate measurement location is not clear based on the results shown thus far. In an attempt to further define when the crack surfaces have completely separated, crack-surface profiles measured as a function of applied load were constructed for each crack length.

In evaluating the crack-surface profiles, a criterion based upon the elastic-crack-tip-displacement relations ${ }^{25}$ is used to determine when the crack is completely open. The elastic-displacement equation appropriate for this evaluation is :

$$
U_{y}=\frac{K_{I}}{G} \sqrt{\frac{r}{2 \pi}} \sin \frac{\theta}{2}\left(\frac{2}{1+\nu}-\cos ^{2} \frac{\theta}{2}\right)
$$

where $U_{y}$ is the component of displacement normal to the crack-surface plane at a point near the crack tip located by the polar coordinates $(r, \theta) . G$ is the shear modulus, $\nu$ is Poisson's ratio, and $K_{I}$ is the Mode I stress-intensity factor. This equation yields a parabolic crack-surface profile with zero displacement at the crack tip. For the criterion established here, it is required that the parabolic relationship extrapolates to the known crack tip on the specimen surface. Profiles constructed in the near-cracktip region at $10,30,50$ and 90 percent of $P_{\max }$ are shown in Fig. 7. The profiles at 50 and 90 percent of $P_{\max }$ meet the above criterion whereas, at 30 percent of $P_{\max }$, the parabolic relationship extrapolates to a crack tip at a location less than the known position of the crack tip on the specimen surface. Therefore, it is determined that the cracks are not open at 30 percent of $P_{\max }$. A detailed evaluation of crack-surface profiles obtained at 5-percent load intervals up to 90 percent of $P_{\max }$ was conducted. An average value of approximately 43 percent of $P_{\max }$ is derived from these profiles as a representative value of the opening load. In Fig. 8, the far-field crack-surface profiles are shown at $10,30,50$ and 90 percent of $P_{\max }$. The clipon displacement-gage measurements are consistent with those made using the IDG. If the crack-surface profile is used to evaluate the load at which the crack becomes fully open, it is evident that the value determined here does not correlate with either the far-field value (approximately $0.23 P_{\max }$ ) or near-crack-tip value (greater than $\left.0.64 P_{\max }\right)$ of $P_{\mathrm{op}}$ shown earlier.

The results of the acoustic-emission measurements are presented in Fig. 9. It is noted that the number of $\mathrm{AE}$ counts per cycle is highly variable. Although the load cycles only go to 91 percent of $K_{\max }$, there are some significant emissions associated with some cycles. The primary cause of the acoustic emission is considered to be crack extension since the emissions generally occurred during the loading portion of the test cycles. Based on average crack-growth-rate data for this material, ${ }^{26} 24$ testload cycles would produce less than $6 \mu \mathrm{m}$ of crack growth. These results indicate the sensitivity of the $\mathrm{AE}$ technique for detecting small increments of crack growth; however, the variability of the count rate illustrates the statistical nature of the crack-propagation process. This highlights the necessity of averaging AE data over large cycle blocks if a quantitative relationship is to be developed between $\mathrm{AE}$ results and fracture-mechanics parameters.

Acoustic emission upon unloading, which has been reported to be related to crack closure, ${ }^{24}$ was not generally observed in this effort. Vary and Klima ${ }^{5}$ observed that the magnitude of acoustic emissions in steel, aluminum and titanium alloys during unloading appears to be related to the crack-surface roughness. The fatigue-crack surfaces of IN-100 are extremely smooth. Therefore, the lack of acoustic emissions during unloading appear to agree with the observations of Vary and Klima. The one notable exception, when emissions were observed during unloading, followed a seven-percent overload during Cycle 5 at $a=$ $27.92 \mathrm{~mm}$. The IDG and clip-on displacement-gage records showed no changes in displacement load-response after the overload. However, during the overload portion of the cycle, $2200 \mathrm{AE}$ counts were recorded. These counts are not shown in Fig. 9 because they occurred at loads greater than the normal test-load range. This acoustic- 


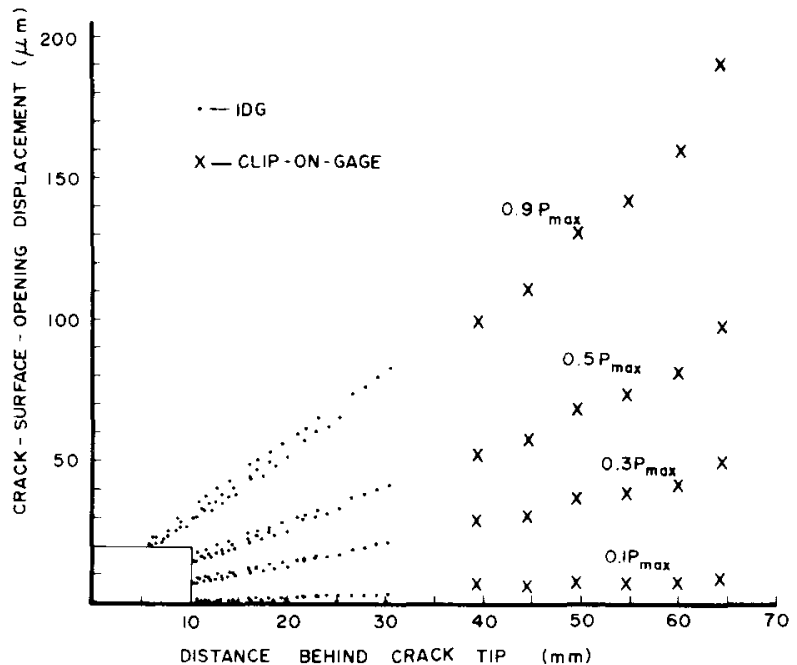

Fig. 8-Crack-surface profiles remote from the crack tip using both IDG and clip-on displacement-gage data

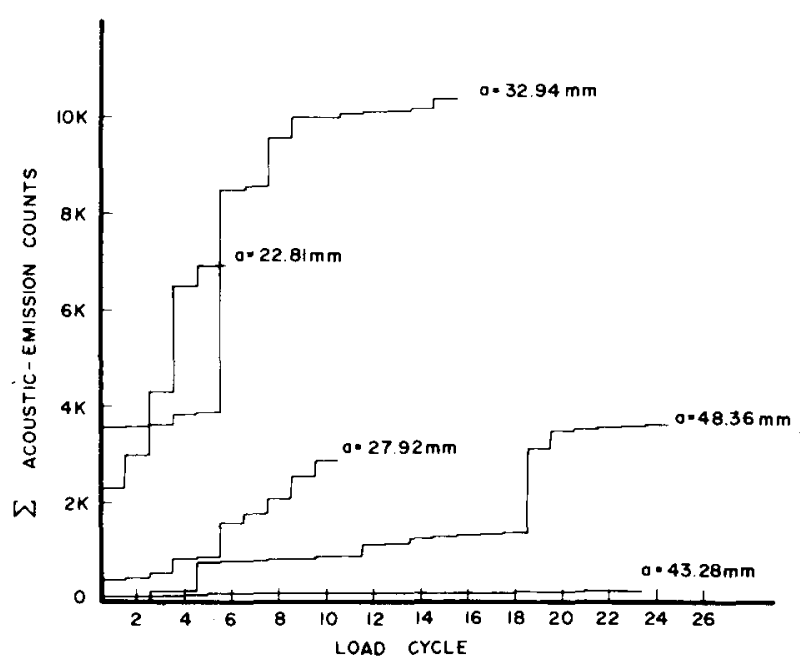

Fig. 9-Acoustic-emission response to cyclic loading

emission activity during loading is indicative of crack-tip deformation. Another indication of increased crack-tip deformation was the occurrence of acoustic-emission activity during the unloading portions of subsequent test cycles. Thirty-five percent of the counts illustrated for the load cycles at this crack length after the overload were recorded during the unloading portion of the cycle. It is significant that only after this slight load perturbation were acoustic emissions observed during unloading that could be attributed to crack closure.

\section{Conclusions}

The objective of this study was to evaluate the uniqueness of $P_{o p}$, as defined by Elber as the point of linearity on the displacement-load relation, as the parameter to quantify the load at which a crack is completely open. The results of the data presented indicate that $P_{o p}$ is not a unique value but a variable dependent on measurement location. Unless a rational physical mechanism is shown to account for the observed variability in $P_{o p}$, it is suggested that $P_{o p}$ does not characterize the load at which the crack is completely open and it is not suitable for quantifying an effective stress-intensity range experienced at the crack tip. Based on the crack-surface profiles constructed from the displacement-load data, it appears that an opening load based on a crack-surface-opening criterion may be more appropriate for quantifying complete crack-surface separation.

A large variability in acoustic emission counts was experienced for cracks grown under identical stressintensity histories. A well-defined relationship does not exist between acoustic-emission counts and crack closure for the conditions studied here.

\section{Acknowledgments}

The authors wish to acknowledge the experimental support provided by Charles Bell and Richard Klinger of Systems Research Laboratories, Inc. J.W. Jones wishes to acknowledge the support provided by the National Research Council and the Air Force Materials Laboratory.

\section{References}

1. Elber, W., Engineering Fracture Mechanics, 2 (I), $37-45$ (Jul. 1970). 2. Elber, W., Damage Tolerance in Aircraft Structures, ASTM STP 486, ASTM, 230-242 (1971).

3. Shih, T.T. and Wei, R.P., Engineering Fracture Mechanics, 6 (I), 19-32 (Mar. 1974).

4. Buck, O., Ho, C.L. and Marcus, H.L., Engineering Fracture Mechanics, 5 (l), 23-34 (Feb. 1973).

5. Vary, A. and Klima, S.J., "A Potential Means of Using Acoustic Emission for Crack Detection Under Cyclic-Load Conditions," NASA TMX-68228, NASA Lewis Research Center, Cleveland, $O H$.

6. Pitoniak, F.J., Grandt, A.F., Montulli, L.T. and Packman, P.F., Engineering Fracture Mechanics, 6 (4), 663-670 (1974).

7. Roberts, $R$. and Schmidt, R.A., International Journal of Fracture, 8, 469-471 (1972).

8. Katcher, $M$. and Kaplan, M., Fracture Toughness and Slow Stable Crack Growth, ASTM STP 559, ASTM, 264-282 (1974).

9. Sharpe, W.N., Jr. and Grandt, A.F., Jr., Mechanics of Crack Growth, ASTM STP 590, ASTM, 302-320 (1976).

10. Marci, G. and Packman, P.F., Materialprüfung, 18, 260-265 (1976).

11. Hagemeyer, J.W., "Growth Rates and Closure Stresses for Fatigue Cracks in Aluminum Alloys," Tech. Rept. No. ERR-FW-1779, General Dynamics, Ft. Worth, TX (1976)

12. Fransden, J.D., Inman, R.V. and Buck, O., Intl. J. of Fract., 11, 345-348 (1975).

13. Bachman, V. and Munz, D., Intl. J. of Fract., 11, 713-7l6 (1975).

14. Clarke, C.K. and Cassatt, G.C., Engineering Fracture Mechanics, 9, 675-688 (1977).

15. Rueping, J.E. and Hillberry, B.M., "Fatigue Crack Closure Behavior: A Comparative Study," Air Force Office of Scientific Research Technical Report No. 76-1090, AFOSR, Bolling Air Force Base, D.C., 20332 (Aug. 1976).

16. Imhof, E.J. and Barsom, J.M., Progress in Flaw Growth and Fracture Toughness Testing, ASTM STP 536, ASTM (1973).

17. Wallace, R.M., Annis, C.G., Jr., and Sims, D.L., "Application of Fracture Mechanics at Elevated Temperatures, " AFML-TR-76-176, Part Il.

18. Sharpe, W.N., Jr., Intl. J. of Nondestr. Test., 3, 56-76 (197l).

19. Macha, D.E., Sharpe, W.N., Jr., Grandt, A.F., Jr., Cracks and Fracture, ASTM STP 601, ASTM, 490-505 (1976)

20. Marci, G., Packman, P.F. and Jones, J.W., Proceedings of the 2nd Intl. Conf. on Mech. Beh. of Matls, Boston (1976).

21. Bateman, D.A., Bradshaw, F.J. and Rooke, D.P., "Some Observations on Surface Deformation Round Cracks in Stressed Sheets, " Royal Aircraft Establishment Technical Note No. CPM. 63, London (1963).

22. Oppel, G.U. and Hill, P.W., EXPERIMENTAL MECHANICS, 4 (7), 206-211 (Jul. 1964).

23. Underwood, J.H., Swedlow, J.L. and Kendall, D.P., Engrg Fract. Mech., 2, 183-196 (1971).

24. Buck, O., Intl. J. of Fract. Mech., 8, 121-124 (1972).

25. Paris, P.C and Sih, G.C., Fracture Toughness Testing and Its Applications, ASTM STP 381, ASTM, 30-81 (1965).

26. Macha, D.E., "Fatigue Crack Growth Retardation Behavior of IN-100 at Elevated Temperatures," to be published in Engrg. Fract. Mech. 